\title{
Comparative Gross Morphological Studies on the Os-Coxae of Flamingo and the Great Indian Horned Owl
}

\author{
K. Rajalakshmi*, P. Sridevi and M. Siva Kumar \\ Department of Veterinary Anatomy and Histology, Rajiv Gandhi Institute of Veterinary \\ Education and Research, Kurumbapet, Puducherry-605010, India \\ *Corresponding author
}

Keywords

Os-Coxae,

Ilium, Anti-

Trochanter,

Ischium

\section{Article Info}

Accepted:

15 February 2020

Available Online:

10 March 2020

\section{A B S T R A C T}

The os-coxae of flamingo and great Indian horned owl it consists of three bones namely ilium, ischium and pubis. In flamingo and great Indian horned owl, the ilium was elongated in shape and consisted of preacetabular and post acetabular parts. The preacetabular part of the ilium in both the species of the present study was quadrilateral in shape. The ischium was flat, almost triangular in outline and was situated ventral to the post acetabular part of the ilium in both species. The ischiatic foramen which was large and oblong in flamingo and small oval in great Indian horned owl. In flamingo and great Indian horned owl the pubis was a thin rib like elongated bone placed along the ventral border of the ischium with which it formed the ischio-pubic incisures. In both species on the caudodorsal aspect of the acetabulum was a large bony prominence, the antitrochanter was large and triangular in shape in the great Indian horned owl a pointed apex.

\section{Introduction}

A remarkable feature of birds is the extensive fusion of the pelvis to the synsacrum and the caudal series of fused vertebrae. The entire unit, pelvis and synsacrum together from a rigid platform for muscles of the hindlimb and tail and forms apart of the system which enables a bird to maintain a stable streamlined posture during flight. The large size of the pelvic girdle is related to the bipedal standing posture, Moreover the ventrally opened pelvis forms a protective roof for large part of the body cavity and the organs contained in it. Keeping in view the paucity of literature pertaining to the oscoxae of flamingo and great Indian horned owl the present study was conducted. 


\section{Materials and Methods}

The materials for the study were collected from flamingo and great indian horned owl brought for post mortem examination to the Department of Veterinary Pathology Rajiv Gandhi Institute of Veterinary Education and Research, Puducherry. The bones were removed and collected by the regular process of maceration, cleaned, dried and the various gross anatomical features were recorded.

\section{Results and Discussion}

The os-coxae of flamingo and great indian horned owl it consists (Fig. 1).of three bones namely ilium, ischium and pubis. The space between the pelvic bones was occupied by rhomboid shaped lumbosacral mass similar findings reported by Mc lelland (1990) in adult chicken. Ilium was fused to the transverse processes and dorsal spinous process of the synsacrum.

\section{Ilium}

In flamingo and great Indian horned owl, the ilium (Fig. 2) was elongated in shape and consisted of preacetabular and post acetabular parts and both the parts were joined with the lumbosacral mass which was also noticed by Mehta et al., 2014 in Japanese quail and Tamilselvan et al., 2015 in ostrich, guinea fowl and pigeon by Lavanaya et al., 2017, Indian eagle owl by Sarma et al., 2018 and by Keneisenuo et al., 2019 in eagle and brown wood owl. In both the species the preacetabular part was much longer than the post- acetabular part as mentioned by Indian eagle owl by Sarma et al., 2018 and by Keneisenuo et al., 2019 in eagle and brown wood owl. The preacetabular part cranially was fused completely with the dorsal spinous process of the limbo-sacral mass which aggress with the findings of Indian eagle owl by Sarma et al., 2018 Keneisenuo et al., 2019 in eagle and brown wood owl. In contract guinea fowl and pigeon by Lavanaya et al., 2017 reported that absence of such fusion. The preacetabular part of the ilium in both the species of the present study was quadrilateral in shape as reported by Sathyamoorthy et al., 2012 in spot- billed pelicans. The dorsal surface of preacetabular part was slightly concave in flamingo which agreed with similar finding by Sathyamoorthy et al., 2012 in spot- billed pelicans, while in great Indian horned owl it was more concave. Nickel et al., 1986 in the domestic birds the dorsal surface presented a deep depression. The post acetabular part was small and its quadrilateral in shape in both species and its dorsal surface was slightly convex as mentioned by Kumar et al., 2016 in barn owl and comparatively in owls the ventral border of the postacetabular part was fused with the dorsal border of ischium which was not fused in flamingo terminal part of the ventral border of the post acetabular part. A sharp prominent crest clearly demarcated the pre and postacetabular part of the ilium on its dorsal surface in great Indian horned owl which agreed with the findings of Keneisenuo et al., 2019 in eagle and brown wood owl. Whereas the crest was not that much prominent in flamingo. In the great Indian horned owl cranially the crest of either sides were very close to one another but caudally they became wide a part and the crest of the post acetabular part formed the lateral border of the post acetabular part which was in accordance to the findings of Sarma et al., 2018 in Indian eagle owl. In flamingo the precaetabular part of ilium presented at the terminal part of its lateral border several pneumatic foramina which were not noticed in great Indian horned owl. The lateral border of preacetabular part was concave, thin cranially while the thickness gradually increased and was thicker near the acetabulum. In great Indian horned owl the anterior one third of the lateral border was straight while behind it was concave and at 
the junction between was observed a small process. The medial border of the both species was convex and was fused with spinous process of synsacrum. The cranial border was covex in flamingo while in owl sloped downward and ended in a triangular bony structure along with anterior part of the lateral border. The ventral surface the ilium was flat and fused with transverse processes of the lumbosacral mass, anteriorly in the both the species. Posteriorly the ventral surface presented a depression the, iliac fossa was deep in the great Indian horned owl while it was wide and shallow in the flamingo. Sathyamoorthy et al., 2012 in spotbilled pelicans Mehta et al., 2014 in Japanese quail and guinea fowl and pigeon by Lavanaya et al., 2017. However the renal fossa was not noticed in emu by Mehta et al., 2013 and bar- headed goose by Sasan et al., 2017. These could be due to species variations.

\section{Ischium}

The ischium was flat, almost triangular (Fig. 2).in outline and was situated ventral to the post acetabular part of the ilium in both species. In great Indian horned owl the ischium was directed downwards and backwards which is in accordance with the findings by Mc Lelland 1990 in domestic fowl, guinea fowl and pigeon by Lavanaya et al., 2017 Keneisenuo et al., 2019 in eagle and brown wood owl. The ischium consisted of vertical part and a horizontal part in flamingo. In the both species cranial part of ischium was narrow contributed in the formation of acetabulum, whereas the dorsal border of its post acetabular part along with the ventral border of ilium enclosed the ischiatic foramen which was large and oblong in flamingo and small oval in great Indian horned owl. In flamingo the horizontal part of the ischium porojected $1 \mathrm{~cm}$ behind he post acetabular part of ilium. In great Indian horned owl ischium extended $1.3 \mathrm{~cm}$ behind the post acetabular part.The dorsal surface of ischium in both species was slightly concave and the ventral border of ischium anteriorly joined with the pubis and enclosed obturator foaramen and continued posteriorly as the ischio-pubic incisures which is in coroborration with the finfings of Nickel et al., 1977 in domestic fowl and duck, guinea fowl and pigeon by Lavanaya et al., 2017, Indian eagle owl by Sarma et al., 2018 and by Keneisenuo et al., 2019 in eagle and brown wood owl. The posterior border of ischium was free in both species was rounded in flamingo while in great Indian horned owl it sided downwards and backwards and ended as a sharp process. The sharp process represented the post angle of ischium which agreed with Sarma et al., 2018 in Indian eagle owl .

\section{Pubis}

In flamingo and great Indian horned owl the pubis was a thin rib like elongated bone placed along the ventral border of the ischium with which it formed the ischio-pubic incisures. Similar findings were observed by Sarma et al., 2018 in Indian eagle owl and Keneisenuo et al., 2019 in brown wood owl. The ischio- pubic inscisure was continued anteriorly with the obturator foramen in the flamingo which agreed with the findings made by guinea fowl and pigeon by Lavanaya et al., 2017. Nickel et al., 1977 in domestic fowl the incisures varied in length in different species and is closed by a membrane. The ischiopubic incisures was very narrow in great Indian horned owl but was longer and wider in the flamingo. The anterior end of the pubis joined the preacteabular part of ilium in both the species. The anterior in flamingo, became thin, flattened and widened while in great Indian horned owl it became thin and narrow. In the great Indian horned owl the pointed posterior end of the pubis was bent medially so that it faced its counter part of the 
opposite side. These findings are in concurrence with Sarma et al., 2018 in Indian eagle owl. in the flamingo, the posterior end of the pubis was thick rod like and unlike in owl was curved outward and its pointed end faced downward. Nickel et al., 1986 in fowl and pigeon the caudal end of pubis was narrow and curved caudomedially and the pubis in goose terminated in a shovel-like process which was curved medially. In the great Indian horned owl and flamingo projected beyond the ilium and ischium which is in accordance to the findings of Sasan et al., 2017 in Bar-head, Sarma et al., 2018 in Indian eagle owl. In the flamingo the pubis projected far a head $4 \mathrm{~cm}$ than in owl $1 \mathrm{~cm}$.
However Mehta et al., 2013 had observed that in emu, the pubis did not extended beyond the ilium and ischium. In flamingo a triangular small blunt pectineal process was noticed at the anterior end of pubis Sreeranjini et al., 2011 in peahen, guinea fowl by Lavanaya et al., 2017 According to Nickel et al., 1977 in domestic fowl the processus pectinealis was long and thorn-like. The pectenial process was not observed in the great Indian horned similar observations reported by Nickel et al., 1977 and Lavanaya et al., 2017 in pigeon, Sathyamoorthy et al., 2012 in pelican and Mehta et al., 2014 in quail. However Keneisenuo et al., 2019 had observed a very small pectineal process in brown wood owl.

Fig.1 Photograph showing of the os-coxae of flamingo and great Indian horned owl 1.Ilium 2. Ischium 3. Pubis
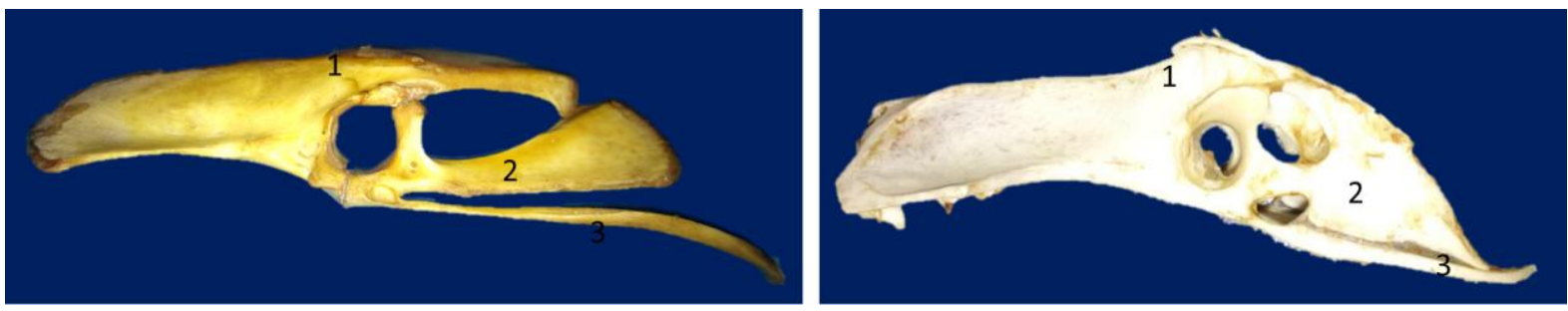

Fig.2 Photograph showing of the os-coxae of flamingo and great indian horned owl 1.Pre-acetabular 2. Post- acetabular 3. Crest 4. Acetabulm 5. Anti- Trochanter 6. Ischiatic Foramen 7. Obtubartor Foramen 8.Ischium 9. Pubis 10. Ischiopubicincisure 12. .Pectinal Process

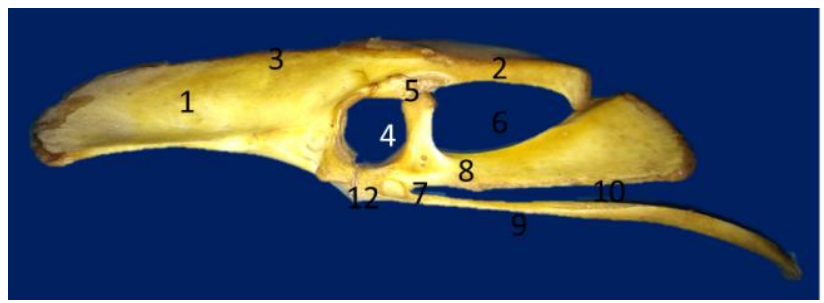

\section{Acetabulum}

In both the species a circular perforated acetabulum was noticed which articulated with the head of the femur. Similar features of the acetabulum were mentioned by Sarma et al., 2018 in Indian eagle owl and Deshmukh et al., 2016 in peacock and peahen and by

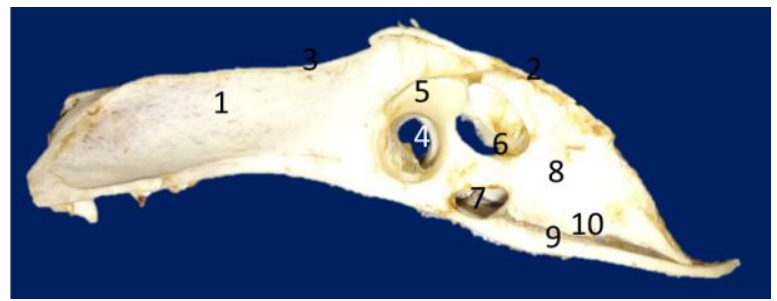

Keneisenuo et al., 2019 in eagle and brown wood owl. In both species on the caudodorsal aspect of the acetabulum was a large bony prominence, the anti- trochanter was large and triangular in shape in the great Indian horned owl a pointed apex which coincides with the findings by Keneisenuo et al., 2019 in eagle and brown wood owl and 
Indian eagle owl by Sarma et al., 2018. The anti trochanter had a facet which articulated with the trochanter major of the femur as reported in pelican (Sathyamoorthy et al., 2012), in cattle egret by (Rezk, 2015), guinea fowl and pigeon (Lavanaya et al., 2017), Indian eagle owl ( Sarma et al., 2018). All the bones were involved in the formation of the perforated acetabulum in both the species which concurs with the findings of Sathyamoorthy et al., 2012 in pelican and but in contrary, pubis was not involved in fowl and duck by Nickel et al., 1977 and Dyce et al., 1996 in domestic fowl.

\section{Acknowledgement}

Authors are thankful to the Dean Rajiv Gandhi Institute of Veterinary Education and Research, Puducherry for providing the basic infrastructure for carrying out this research work

\section{References}

Deshmukh, S.K., Karmore, S.K., Gupta, S.K., Kodape, S. and Prakash, R. 2016. Comparative biometrical studies on the oscoxae and synsacrum of peacock and peahen. Vet. Pract., 17(1): 41-42

Dyce, K.M., Sack, W.O. and Wensing, C.J.G. (2002). Textbook of Veterinary Anatomy. 3rd ed., W. B. Saunders Company, Philadelphia. 840p.

Keneisenuo O.P. Choudhary, S. Debroy, R.S. Arya1, P.C. Kalita, P.J. Doley, T.K. Rajkhowa1 and A. Kalita 2019 Comparative Gross Morphological Studies on the OsCoxae of Crested Serpent Eagle (Spilornis cheela) and Brown Wood Owl (Strix leptogrammica) Journal of Animal Research: v.9 n.3, p. 439-442.

Kumar, M.L.B., Lakshmi, M.S. and Kumar, D.P. 2016. Gross anatomy of different bones in the barn owl (Tyto alba). Int. J. Sci. Env. Tech., 5(4): 1893-1896.

Lavanya, C., Jayachitra, S., Iniyah, K. and Balasundaram, K. 2017. Comparative anatomy of oscoxae in guinea fowl and pigeon. Int. J. Curr. Microbiol. App. Sci., 6(9): 3655-3659

McLelland, J. 1990. A Colour Atlas of Avian Anatomy. Wolf Publishing Ltd., London, England.

Mehta, S., Guha, K., Shalini, S. and Kumar, C. 2014. Gross anatomical studies on the os coxae and synsacrum of Japanese quail. Ind. J. Vet. Anat., 26(2): 126127.

Nickel, R., Schumer, A. and Seiferle, E. 1977.Anatomy of domestic birds. Berlim: Hamburg, Germany

Rezk HM. Anatomical investigation on the appendicular skeleton of the cattle egret (Bubulcus ibis). J Exp Clin Anat 2015; 14:512

Sarma, K., Suri, S. and Sasan, J.S. 2018. Gross anatomical studies on os coxae of Indian Eagle owl (Bubo bengalensis). Explor. Anim. Med. Res., 8(2): 208-210

Sathyamoorthy, O.R., Thirumurugan. R., Kumar, K.S. and Jayathangaraj, M.G. 2012.Gross morphological studies on the pelvic girdle of spot-billed pelicans (Pelecanus philippensis). Ind. J. Vet. Anat., 24: 109-110

Sreeranjini, A.R., Ashok, N., Indu, V.R., Lucy, K.M., Syam, K.V., Chungath, J.J. and Harshan, K.R. 2011. Morphological studies on the pelvic girdle of a peahen. J. Ind. Vet. Assoc. Kerala, 9(3): 46-48.

Tamilselvan, S., Iniyah, K., Jayachitra, S., Sivagnanam, S., Balasundaram, K. and. Lavanya, C. 2015. Gross anatomy of os coxae of ostrich (Struthio camellus). Int. J. Curr. Microbiol. App. Sci., 4(4): 201-205.

\section{How to cite this article:}

Rajalakshmi, K., P. Sridevi and Siva Kumar, M. 2020. Comparative Gross Morphological Studies on the Os-Coxae of Flamingo and the Great Indian Horned Owl. Int.J.Curr.Microbiol.App.Sci. 9(03): 1879-1883. doi: https://doi.org/10.20546/ijcmas.2020.903.218 